\title{
Circadian rhythm of VEGF expression in the liver of hepatectomized-tumor-bearing adult and young mice
}

\author{
Ayelén Fernández Blanco ${ }^{a}$, Laura Andrinia , Ana Lía Errecalde ${ }^{a}$, Ana María Inda a,b and \\ Marcela García ${ }^{a}$ \\ aFacultad de Ciencias Médicas, Cátedra de Citología, Histología y Embriología "A", Universidad Nacional de La \\ Plata, Buenos Aires, Argentina; ${ }^{b} \mathrm{CIC}$, Buenos Aires, Argentina
}

\begin{abstract}
We analyzed VEGF expression in regenerating liver (after partial hepatectomy) of tumor-bearing adult and young mice, throughout one complete circadian cycle. The animals were sacrificed every $4 \mathrm{~h}$, from 26 to $46 \mathrm{~h}$ post-hepatectomy. Liver samples were processed for immunohistochemistry. The results showed circadian variation of VEGF expression in hepatectomized mice (control group) and hepatectomized-tumor-bearing mice. The maximum value of VEGF expression was found at $16: 00 / 30 \mathrm{~h}$ of day/hour post-hepatectomy $(\mathrm{HD} / \mathrm{HPH})$ in tumor-bearing young mice, and at 20:00/34 HD/HPH in the controls. In adult mice the maximum values of VEGF expression were at 16:00/30 HD/HPH in tumor-bearing mice, and at 08:00/46 HD/ $\mathrm{HPH}$ in the controls. Young tumor-bearing mice showed significantly higher mean values than the controls. In conclusion, the presence of the tumor in the animals induces modifications in the intensity and the temporal distribution of the circadian curves of VEGF expression.
\end{abstract}

\section{ARTICLE HISTORY}

Received 30 August 2017 Accepted 4 September 2017

\section{KEYWORDS}

Mouse; age; hepatocellular carcinoma; hepatectomy; angiogenesis

\section{Introduction}

In numerous cell populations, in response to specific conditions associated with different stages of the organism's life span, cell cycle length may vary. It is regulated by growth factors and other signaling molecules that stimulate or inhibit cellular proliferation (García et al. 2001). In mammals, circadian rhythms are generated by a central clock in the suprachiasmatic nucleus located in the hypothalamus that constantly synchronize with environmental cues via circadian input pathways and controls the peripheral clocks through circadian output pathways (Reppert and Weaver 2002; Buijs et al. 2006).

The liver is an organ with a high regenerative capacity. Partial hepatectomy $(\mathrm{PH})$ alters the serum concentrations of substances involved in cellular proliferation, leading to the compensatory liver hyperplasia (Fausto et al. 2012). Liver regeneration after PH offers a unique and robust model to study initiation, progression and termination of tissue growth in vivo. A major goal is to understand this process in humans in order to apply this knowledge in regenerative medicine, or to oppose deregulated proliferation and growth in tumorigenesis (Kurinna and Barton 2011). 
A particularly useful model to study liver regeneration in mice and rats involves removal of the large and median lobes of the liver, which comprise approximately two-thirds of the organ. As a consequence, quiescent and highly differentiated liver cells of the remaining liver proliferate to restore the original liver mass within a few days (approximately 10 days in rodents). Hepatocytes are the first to enter in the cell cycle and undergo one to two rounds of cell division within 2-3 days (Böhm et al. 2010). Partial hepatectomy is a widely used method for liver regeneration studies because it is not accompanied by massive inflammation or necrosis processes.

In liver regeneration, the development of new capillary blood vessels by sprouting from existent microvessels is a fundamental requirement for cellular proliferation (Ribatti and Crivellato 2012). This complicated process, defined as angiogenesis, is promoted by VEGF (vascular endothelial growth factor), which is the most potent and specific growth factor for both angiogenesis and vasculogenesis (Shibuya 1995). The mRNA of what is expressed after $\mathrm{PH}$ in hepatocytes and non-parenchymal cells suggests that VEGF plays a significant role in liver regeneration (Mochida et al. 1996; Furnus et al. 2003). Alterations in angiogenesis can include reduced expression of VEGF in the injured or diseased aged animals relative to young controls (Sadoun and Reed 2003). So, in this study we used young and adult mice to compare the possible differences in VEGF expression due to age along a circadian period (Schmitt and Cantley 2008; Schmucker and Sanchez 2011). On the other hand, it has been demonstrated that tumor bearing in adult mice could modify the intensity and temporal distribution of VEGF expression (Andrini et al. 2010).

In this work, we used a hepatocellular carcinoma, which was characterized in our laboratory from the morphological point of view (following the classification by Reuber 1966). It is an encapsulated tumor, of firm consistency, with large areas of necrosis and hemorrhages. This rapidly growing undifferentiated hepatocellular carcinoma is maintained by subcutaneous serial transplant in male mice.

For all the above mentioned, the aim of this study was to analyze the magnitude and temporal distribution of VEGF expression in the regeneration liver (after PH) of adult and young male mice bearing ES2 hepatocellular carcinoma, throughout one complete circadian cycle.

\section{Materials and methods}

\section{Animals}

For these experiments, we used adult ( 90 days old) and young male ( 28 days old) $\mathrm{C} 3 \mathrm{H} / \mathrm{S}$ strain mice. They were subjected to the following standardization conditions: water and food available ad libitum, ambient temperature maintained at $22 \pm 2{ }^{\circ} \mathrm{C}$, alternating light and dark periods restricted to $12 \mathrm{~h}$ each with illumination by fluorescent lamps beginning at 06:00 h (Echave Llanos et al. 1963).

The conditions concerning animal management fully respected the policy and mandates of the Guide for the Care and Use of Laboratory Animal Research of the National Research Council. 


\section{Tumor-bearing animals}

After an appropriate period of synchronization (between 7 days in young mice and 15 days in adult mice), about $70 \mathrm{mg}$ of the $\mathrm{C} 3 \mathrm{H} / \mathrm{S}$ histocompatible ES2a hepatocellular carcinoma was grafted into the subcutaneous tissue of each animal's flank. The graft-bearing animals were subsequently divided into lots of five to eight mice each; then, they were housed under standardization conditions before the lots were separated into the experimental-protocol groups.

\section{Tissue samples}

The animals were sacrificed at 12:00/26, 16:00/30, 20:00/34, 00:00/38, 04:00/42, and 08:00/46 $\mathrm{HD} / \mathrm{HPH}$. Samples of liver were removed promptly, fixed in $10 \%$ buffered formalin for $24 \mathrm{~h}$, processed routinely and embedded in paraffin. Five-micrometer sections were cut, placed on positive-charge slides and dried in an oven at $58^{\circ} \mathrm{C}$ overnight.

\section{Determination of VEGF expression}

Sections were deparaffinized in xylene and rehydrated. Slides were washed in Tris buffer saline (TBS) and irradiated in a household microwave oven (750 W), in buffer citrate for $20 \mathrm{~min}$, then washed in TBS and incubated with primary antibody (VEGF-A clone C-1, Santa Cruz Biotechnology, California, USA) at 1/80 dilution in a humid chamber overnight, at room temperature. As detection system, Envision ${ }^{\mathrm{TM}}$ (DAKO, Carpinteria, California, USA) was used. The reaction was developed using 3'3-diaminobenzidine (DAB, DAKO) in TBS with $0.03 \%$ $\mathrm{H}_{2} \mathrm{O}_{2}$. The sections were slightly counterstained with Mayer's hematoxylin and mounted. Negative controls were run in parallel, omitting primary antibody.

The positive control was a section of liver that had previously shown to have a high VEGF content, by immunohistochemistry. VEGF staining was seen in the cytoplasm of tumor cells.

\section{Experimental groups}

The animals were divided into two experimental groups: group I (young mice): (a) hepatectomized (controls) and (b) hepatectomized and tumor-bearing animals and group II (adult mice): (a) hepatectomized (controls) and (b) hepatectomized and tumor-bearing animals. Each group (young and adult mice) were divided into 6 (six) lots of about 5-6 mice each. Then, they were housed for further 1 or 2 weeks (group I and II, respectively) under standardization conditions. All the animals were subjected to a $\mathrm{PH}$ at 10:00 $\mathrm{h}$. The animals were sacrificed every $4 \mathrm{~h}$ starting at 12:00/26 h of day/hours post-hepatectomy (HD/HPH) until 08:00/46 HD/HPH.

\section{Statistical analysis}

The liver sections were examined microscopically under an oil-immersion objective (at $1500 \times$ ) to score the total number of labeled cells within a minimum of 3000 cells. The expression of VEGF was assessed according to the percentage of immunoreactive cells in a total of 1000 cells (quantitative analysis). The statistical analysis of VEGF expression was performed 
using Student's $t$-test, Anova and Tukey as a post-comparison test. The results were expressed as a percentage of labeled cells.

\section{Results}

As we can see in the Tables 1 and 2, our results show circadian variation in VEGF expression between both experimental groups. In group I we can observe that the mean values of the tumor-bearing animals were significantly higher than the controls $(p<0.05)$ (Table 1$)$. The maximum value of VEGF expression was found at 16:00/30 in tumor-bearing mice, and at 20:00/34 HD/HPH in the controls (Figure 1). In group II, not statistically significant differences were observed between the values of controls and treated animals (Table 2). The maximum values of VEGF expression were found at 16:00/30 in tumor-bearing mice, and at 08:00/46 $\mathrm{HD} / \mathrm{HPH}$ in the controls (Figure 2). As we can see in Table 3, statistically significant differences $(p<0.05)$ in VEGF expression were observed between young and adult control mice, whereas in tumor-bearing mice not statistically differences were found (Table 4).

\section{Discussion}

Hepatic remodeling, followed by $\mathrm{PH}$, involves a complex set of events including the activation and secretion of numerous growth factors, intense cell proliferation, and finally the restoration of liver architecture. Angiogenesis is a fundamental part of this regenerative process to ensure the correct supply of blood for growing tissues. This process is stimulated by VEGF, the most important angiogenic growth factor (Fausto et al. 2006, 2012; Bockhorn et al. 2007; Aryal et al. 2016).

Different studies performed in rodents demonstrated circadian variations of VEGF expression in hepatocytes of regenerating livers following a partial hepatectomy in tumor and non-tumor-bearing adult mice, as well as in intact adult mice (Furnus et al. 2003; Andrini et al. 2011; Fernández Blanco et al. 2011). Taking this into consideration, we decided to compare VEGF expression in hepatocytes of young and adult hepatectomized and hepatectomized-tumor-bearing mice. The results presented in this work show a circadian rhythm in VEGF expression of regenerating hepatocytes of young and adult mice. In the young hepatectomized no-bearing-tumor mice, the maximum expression value of VEGF in the circadian curve is at $34 \mathrm{~h}$ post-surgery; while in the group of adult animals, the peak is observed $46 \mathrm{~h}$ post-hepatectomy. These results coincide with other authors such as Kraizer et al. (2001) who showed

Table 1. Daily mean values of VEGF expression in hepatectomized (control) and hepatectomized and tumor-bearing young mice.

\begin{tabular}{lcccccc}
\hline Lots & $\mathrm{HD} / \mathrm{HPH}$ & Control $(X \pm \mathrm{SE})$ & $n$ & TBM $(X \pm \mathrm{SE})$ & $n$ & $p$ \\
\hline 1 & $12: 00 / 26$ & $0.9 \pm 0.6$ & 8 & $1.9 \pm 0.9$ & 7 & $<0.05$ \\
2 & $16: 00 / 30$ & $1.1 \pm 0.5$ & 6 & $4.5 \pm 1$ & 6 & $<0.05$ \\
3 & $20: 00 / 34$ & $1.2 \pm 0.5$ & 7 & $1 \pm 0.7$ & 6 & $<0.05$ \\
4 & $00: 00 / 38$ & $0.1 \pm 0.6$ & 6 & $1.5 \pm 0.5$ & 6 & $<0.05$ \\
5 & $04: 00 / 42$ & $0.1 \pm 0.6$ & 6 & $1.5 \pm 0.5$ & 6 & $<0.05$ \\
6 & $08: 00 / 46$ & $0.6 \pm 0.4$ & 6 & $1.5 \pm 0.5$ & 6 & $<0.05$ \\
$X$ & & $0.1 \pm 0.1$ & & $5.2 \pm 0.4$ & & $<0.05$ \\
$p$ & & ns & & $<0.05$ & &
\end{tabular}

Notes: HD/HPH: hour of day/hours post-hepatectomy; $X$ : mean; ES: standard error; $n$ : samples; $p$ : probability; ns: not significant differences; TBM: tumor-bearing mice. 
Table 2. Daily mean values of VEGF expression in hepatectomized (control) and hepatectomized and tumor-bearing adult mice.

\begin{tabular}{lcccccc}
\hline Lots & $\mathrm{HD} / \mathrm{HPH}$ & Control $(X \pm \mathrm{SE})$ & $n$ & TBM $(X \pm \mathrm{SE})$ & $n$ & $p$ \\
\hline 1 & $12: 00 / 26$ & $1.8 \pm 0.2$ & 8 & $2.1 \pm 0.1$ & 7 & $\mathrm{~ns}$ \\
2 & $16: 00 / 30$ & $1.9 \pm 0.2$ & 6 & $3.7 \pm 0.1$ & 6 & $\mathrm{~ns}$ \\
3 & $20: 00 / 34$ & $1.7 \pm 0.3$ & 7 & $2.2 \pm 0.2$ & 6 & $\mathrm{~ns}$ \\
4 & $00: 00 / 38$ & $1.9 \pm 0.3$ & 6 & $1.2 \pm 0.2$ & 6 & $\mathrm{~ns}$ \\
5 & $04: 00 / 42$ & $2 \pm 0.1$ & 6 & $2.02 \pm 0.2$ & 6 & $\mathrm{~ns}$ \\
6 & $08: 00 / 46$ & $2.6 \pm 0.1$ & 6 & $1.8 \pm 0.1$ & 6 & $\mathrm{~ns}$ \\
$X$ & & $1.9 \pm 0.2$ & & $2.2 \pm 0.1$ & & $\mathrm{~ns}$ \\
$p$ & $<0.05$ & & $<0.001$ & & \\
\hline
\end{tabular}

Notes: HD/HPH: hour of day/ hours post-hepatectomy; $X$ : mean; ES: standard error; $n$ : samples; $p$ : probability; ns: not significant differences; TBM: tumor-bearing mice.

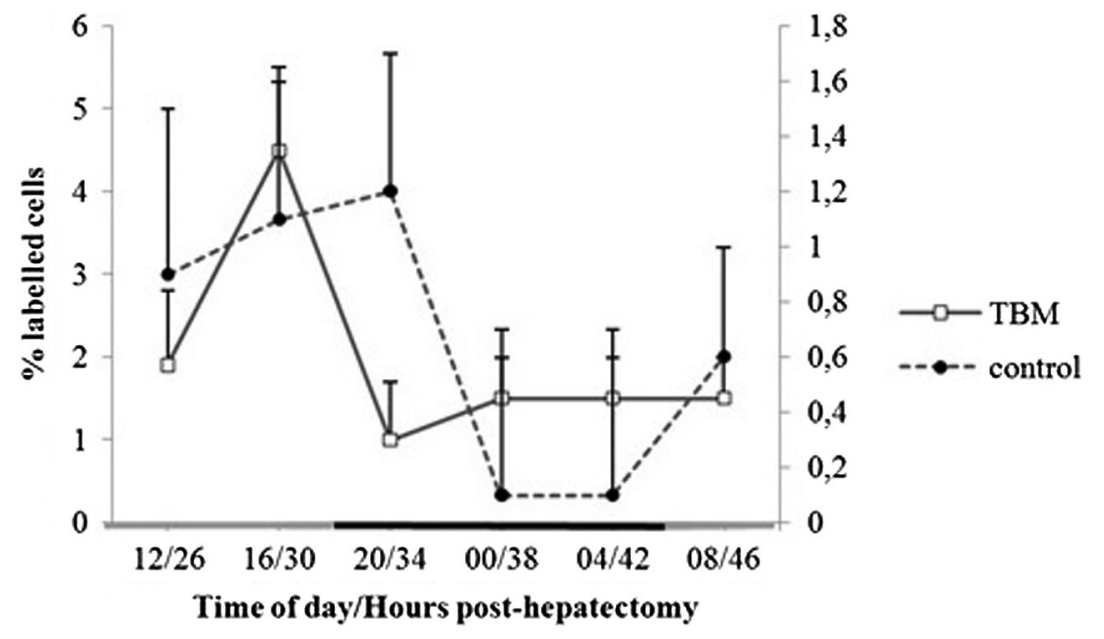

Figure 1. Comparison of VEGF expression values in young hepatectomized (control) and hepatectomized tumor-bearing young mice along a circadian time span. Each time point corresponds to the $X \pm E S$ of VEGF expression values given in Table 1. The illuminating period regimen is indicated on the bottom line: light 06:00-18:00 h, dark 18:00-06:00 h.

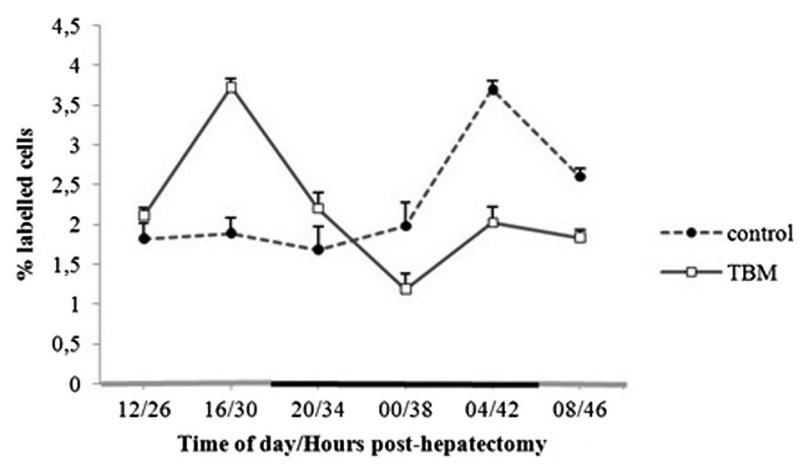

Figure 2. Comparison of VEGF expression values in adult hepatectomized (control) and hepatectomized tumor-bearing adult mice along a circadian time span. Each time point corresponds to the $X \pm E S$ of VEGF expression values given in Table 2. The illuminating period regimen is indicated on the bottom line: light 06:00-18:00 h, dark 18:00-06:00 h. 
Table 3. Daily mean values of VEGF expression in hepatectomized (control) young and adult mice.

\begin{tabular}{lcccccc}
\hline Lots & $\mathrm{HD} / \mathrm{HPH}$ & Young $(X \pm \mathrm{ES})$ & $n$ & Adult $(X \pm \mathrm{ES})$ & $n$ & $p$ \\
\hline 1 & $12: 00 / 26$ & $0.9 \pm 0.6$ & 8 & $1.8 \pm 0.2$ & 8 & $<0.05$ \\
2 & $16: 00 / 30$ & $1.1 \pm 0.5$ & 6 & $1.9 \pm 0.2$ & 6 & $<0.05$ \\
3 & $20: 00 / 34$ & $1.2 \pm 0.5$ & 7 & $1.7 \pm 0.1$ & 7 & $<0.05$ \\
4 & $00: 00 / 38$ & $0.1 \pm 0.6$ & 6 & $1.9 \pm 0.3$ & 6 & $<0.05$ \\
5 & $04: 00 / 42$ & $0.1 \pm 0.6$ & 6 & $2 \pm 0.1$ & 6 & $<0.05$ \\
6 & $08: 00 / 46$ & $0.6 \pm 0.4$ & 6 & $2.6 \pm 0.1$ & 6 & $<0.05$ \\
$X$ & & $0.1 \pm 0.1$ & & $2.3 \pm 0.3$ & & $<0.05$ \\
$p$ & & $\mathrm{~ns}$ & & $\mathrm{~ns}$ & & \\
\hline
\end{tabular}

Notes: HD/HPH: hour of day/hours post-hepatectomy; $X$ : mean; ES: standard error; $n$ : samples; $p$ : probability; ns: not significant differences.

Table 4. Daily mean values of VEGF expression in hepatectomized-tumor-bearing young and adult mice.

\begin{tabular}{lcccccc}
\hline Lots & $\mathrm{HD} / \mathrm{HPH}$ & Young $(X \pm \mathrm{ES})$ & $n$ & Adult $(X \pm \mathrm{ES})$ & $n$ & $p$ \\
\hline 1 & $12: 00 / 26$ & $1.9 \pm 0.9$ & 7 & $2.1 \pm 0.1$ & 7 & $\mathrm{~ns}$ \\
2 & $16: 00 / 30$ & $4.5 \pm 1$ & 6 & $3.7 \pm 0.1$ & 6 & $\mathrm{~ns}$ \\
3 & $20: 00 / 34$ & $1 \pm 0.7$ & 6 & $2.2 \pm 0.2$ & 6 & $\mathrm{~ns}$ \\
4 & $00: 00 / 38$ & $1.5 \pm 0.5$ & 6 & $1.2 \pm 0.2$ & 6 & $\mathrm{~ns}$ \\
5 & $04: 00 / 42$ & $1.5 \pm 0.5$ & 6 & $2.02 \pm 0.2$ & 6 & $\mathrm{~ns}$ \\
6 & $08: 00 / 46$ & $1.5 \pm 0.5$ & 6 & $1.8 \pm 0.1$ & 6 & $\mathrm{~ns}$ \\
$X$ & & $5.2 \pm 0.4$ & & $2.2 \pm 0.8$ & & $\mathrm{~ns}$ \\
$p$ & $<0.05$ & & $<0.001$ & & \\
\hline
\end{tabular}

Notes: HD/HPH: hour of day/ hours post-hepatectomy; $X$ : mean; ES: standard error; n: samples; p: probability; ns: not significant differences.

an increase after hepatectomy in the expression of VEGF mRNA in hepatocytes between 24 and $72 \mathrm{~h}$ after surgery.

As we can infer from the above-mentioned results, the maximum VEGF expression value in adult mice occurs $12 \mathrm{~h}$ after that of the young. This difference in the location of the VEGF expression peaks in the young and adult animals within the circadian curve could be due by the age of the animals. We suggest that adult animals may have a delayed angiogenesis because mature cells do not respond as quickly to as younger cells (Rivard et al. 1999; Sadoun and Reed 2003).

On the other hand, in the present work we demonstrated that the VEGF expression of the regenerating hepatocytes of mice bearing a subcutaneous tumor is expressed in a circadian manner in young and adult animals. However, these curves are different from those that of the control group, since the maximum VEGF expression values in tumor-bearing mice are advanced (to 30 and $34 \mathrm{~h}$ post-hepatectomy). It is possible that the advance in time of this angiogenic factor is required to form new blood vessels to supply nutrients and oxygen to growing liver. Maybe, tumor cells from hepatocellular carcinoma ES2 produce substances that are released into the general circulation and recognize the hepatocytes of regenerating liver, stimulating them to express VEGF (Errecalde et al. 2014). In relation to this, it is known that tumor growth, and its evolution, is a complex phenomenon controlled by an intricate pattern of competing processes (Pérez de Castro et al. 2007), in which a significant increase of growth factors is produces in plasma levels (Michalopoulos 2011). Some of these factors can "cross-talk" between the growing tumor and the regenerating liver (Andrini et al. 2010). It is possible that, within the host, the hepatocarcinoma directly or indirectly modifies VEGF expression of hepatocytes and thus contributes to maintain angiogenesis and its own growth (Tsuzuki et al. 2000). 
The importance of the use of an animal model in these experiments is that the PH reproduces the surgery performed in patients to extirpate the primary hepatic tumor, whereas the grafted hepatocarcinoma would represent the hepatic metastasis. Besides, this model presents a close approach to the micro-environmental conditions, facilitating the interpretation of the events that occur after an extirpation of primary hepatic tumor in patients. This could allow us to test different treatments in mice to be extrapolated to the patients.

Based on our results, we can affirm that the mice bearing a hepatocellular carcinoma presents modified VEGF expression patterns of hepatocytes in their intensity and temporality. Thus, the knowledge of the chronobiology of VEGF expression during hepatic regeneration after hepatectomy is of great importance to determine the right moment for the oncologic drug application, considering the age of the patient and the presence or absence of hepatic metastasis.

\section{Acknowledgments}

We thank the technical staff of the Cátedra "A" de Citología, Histología y Embriología, Facultad de Ciencias Médicas, Universidad Nacional de La Plata (Buenos Aires, Argentina) and the teacher María Laura Colaci for language assistance.

\section{Disclosure statement}

No potential conflict of interest was reported by the authors.

\section{Funding}

This work was supported by the Incentive Programme for Professors Research of the National Education Ministry [code $11 \mathrm{M} / 104]$.

\section{References}

Andrini L, García M, Inda A, Errecalde AL. 2010. Circadian rhythm of VEGF expression in the liver of hepatectomized-tumor-bearing mice. Biol Rhythm Res. 41:57-62.

Andrini L, Fernandez Blanco A, Inda A, García M, Errecalde A. 2011.VEGF expression in hepatectomizedtumor-bearing mice. J Immunoassay Inmunochem. 36:456-463.

Aryal B, Shimizu T, Kadono J, Furoi A, Komokata T, Inoue M, Ikeda S, Fukukura Y, Nakamura M, Yamakuchi $\mathrm{M}$, et al. 2016. A switch in the dynamics of intra-platelet VEGF-A from cancer to the later phase of liver regeneration after partial hepatectomy in humans. PLoS One. 11(3):e0150446.

Bockhorn M, Schöllmann S, Opitz B, Sotiropoulos G, Sheu S, Niehaus E, Trippler M, Frilling A, Broelsch C, Schlaak J. 2007. Vascular endothelial growth factor does not improve liver regeneration and survival after 90\% subtotal liver resection. Hepatol Res. 37:353-359.

Böhm F, Köhler UA, Speicher T, Werner S. 2010. Regulation of liver regeneration by growth factors and cytokines. EMBO Mol Med. 2:294-305.

Buijs RM, Scheer FA, Kreier F, Yi C, Bos N, Goncharuk VD, Kalsbeek A. 2006. Organization of circadian functions: interaction with the body. Prog Brain Res. 153:341-360.

Echave Llanos J, Bade E, Bordin C. 1963. Standardization for periodicity analysis and scatter of values in the study of hepatic regeneration. Acta Physiol Lat Am. 13:385-387.

Errecalde AL, García MN, Inda AM, García AL, Fernández Blanco A, Andrini LB. 2014. Study of angiogenesis and cell proliferation in hepatectomized and tumor-bearing mice. Revista Científica S.A.F. y T. 1(70):27-32.

Fausto N, Campbell J, Riehle K. 2006. Liver regeneration. Hepatology. 43(2 Suppl 1):S45-S53. 
Fausto N, Campbell JS, Riehle KJ. 2012. Liver regeneration. J Hepatol. 57:692-694.

Fernández Blanco A, García AL, Inda AM, Errecalde AL. 2011. Vascular endothelial growth factor expression along a circadian time span in intact adult mice liver. Biol Rhythm Res. 42:141-146.

Furnus C, Inda A, Andrini L, Garcia M, Garcia L, Badrán A, Errecalde A. 2003. Chronobiology of the proliferative events related to angiogenesis in mice liver regeneration after partial hepatectomy. Cell Biol Int. 27:383-386.

García M, Barbeito C, Andrini L, Badrán A. 2001. Circadian rhythm of DNA synthesis and mitotic activity in tongue keratinocytes. Cell Biol Int. 25:179-183.

Kraizer Y, Mawasi N, Seagal J, Paizi M, Assy N, Spira G. 2001. Vascular endothelial growth factor and angiopoietin in liver regeneration. Biochem Biophys Res Commun. 287:209-215.

Kurinna S, Barton MC. 2011. Cascades of transcription regulation during liver regeneration. Int J Biochem Cell Biol. 43:189-197.

Michalopoulos GK. 2011. Liver regeneration: alternative epithelial pathways. Int J Biochem Cell Biol. 43:173-179.

Mochida S, Ishikawa K, Inao M, Shibuya M, Fujiwara K. 1996. Increased expressions of vascular endothelial growth factor and its receptors, flt- 1 and KDR/flk-1, in regenerating rat liver. Biochem Biophy Res Commun. 226:176-179.

Pérez de Castro I, de Cárcer G, Malumbres M. 2007. A census of mitotic cancer genes: new insights into tumor cell biology and cancer therapy. Carcinogenesis. 28:899-912.

Reppert SM, Weaver DR. 2002. Coordination of circadian timing in mammals. Nature. 418:935-941.

Reuber M. 1966. Histopathology of transplantable hepatic carcinomas induced by chemical carcinogens in rats. Gann Monograps. 1:43-54.

Ribatti D, Crivellato E. 2012. "Sprouting angiogenesis", a reappraisal. Dev Biol. 372:157-165.

Rivard A, Fabre JE, Silver M, Chen D, Murohara T, Kearney M, Magner M, Asahara T, Isner JM. 1999. Agedependent impairment of angiogenesis. Circulation. 99:111-120.

Sadoun E, Reed MJ. 2003. Impaired angiogenesis in aging is associated with alterations in vessel density, matrix composition, inflammatory response, and growth factor expression. J Histochem Cytochem. 51:1119-1130.

Schmitt R, Cantley LG. 2008. The impact of aging on kidney repair. Am J Physiol Renal Physiol. 294:F1265-F1272.

Schmucker DL, Sanchez H. 2011. Liver regeneration and aging: a current perspective. Curr Gerontol Geriatr Res. 2011:ID 526379, 8 p. DOI:10.1155/2011/526379.

Shibuya M. 1995. Rol of VEGF-flt receptor system in normal and tumor angiogenesis. Adv Cancer Res. 67:281-316.

Tsuzuki Y, Fukumura D, Oosthuyse B, Koike C, Carmeliet P, Jain RK. 2000. Vascular endothelial growth factor (VEGF) modulation targeting hypoxia inducible factor- $1 \alpha \rightarrow$ hypoxia response element $\rightarrow$ VEGF cascade differentially regulates vascular response and growth rate in tumors. Cancer Res. 60:62486252. 